\section{A) Check for updates}

Cite this: Green Chem., 2020, 22 6519

Received 29th July 2020, Accepted 16th September 2020 DOI: $10.1039 / \mathrm{dOgc02603d}$ rsc.li/greenchem

\title{
Mobility and adsorption of liquid organic hydrogen carriers (LOHCs) in soils - environmental hazard perspective $\uparrow$
}

\author{
Ya-Qi Zhang, (D) a,b Stefan Stolte, ${ }^{\text {a,b }}$ Gizem Alptekin, ${ }^{a}$ Alica Rother, ${ }^{a}$ \\ Michael Diedenhofen, (D) ${ }^{c}$ Juliane Filser (D) ${ }^{d}$ and Marta Markiewicz (D) *a,b
}

\begin{abstract}
Liquid organic hydrogen carriers (LOHCS) are an energy system that can be used to store and transport hydrogen under standard temperature and pressure chemically bound to a carrier. The LOHC systems show advantages over conventional energy systems (recyclability, higher sustainability and lower emissions) and other hydrogen-based systems (lower loses, ease of handling and higher safety), and are applied in stationary and mobile applications worldwide. The scale and type of use indicate that the release of LOHCs to the environment can be expected. Yet, their behaviour and fate have not been investigated especially with regard to assessment of exposure, mobility and possibility to reach surface water, groundwater or drinking water sources. To investigate that we studied the mobility of thirteen technologically promising LOHC candidates including indole, quinaldine, carbazole derivatives, benzyltoluene and dibenzyltoluene, and their (partially) saturated forms in soil, for the first time. The substances were classified into mobility classes based on their organic carbon-water partition coefficients $\left(K_{\text {oc }}\right)$ determined via in silico models and HPLC screening. The log $K_{\mathrm{oc}}$ values increased in the order indoles $<$ quinaldines < carbazole derivatives < benzyltoluenes < dibenzyltoluenes covering a full spectrum of mobility scale (from highly mobile to immobile). The behaviour of exemplary LOHC system - quinaldine including $\mathrm{H}_{2}$-unsaturated, partially and fully saturated forms - was further assessed by investigating the soil-water partition coefficients $\left(K_{\mathrm{d}}\right)$ via adsorption batch equilibrium and column leaching test. The study showed that some LOHCs can be expected to be very mobile in soils and have the potential to reach groundwater.
\end{abstract}

\section{Introduction}

LOHC systems are promising alternatives developed in recent years to support and improve the current options for energy storage and transport. ${ }^{1-3}$ Unlike traditional energy systems in which fossil fuels are the main energy source, hydrogen that is covalently bound to LOHCs is used as the energy vector. ${ }^{1,2}$ Compared to fossil fuels, hydrogen shows higher gravimetric energy density (120 MJ kg $\left.{ }^{-1}\right)^{4-6}$ and inherently lower emissions

\footnotetext{
${ }^{a} U F T$ - Center for Environmental Research and Sustainable Technology, Department of Sustainable Chemistry, University of Bremen, Leobener Str. 6, D-28359 Bremen, Germany.E-mail: marta.markiewicz@tu-dresden.de

${ }^{b}$ Institute of Water Chemistry, Technische Universität Dresden, Berg Str. 66, D-01069 Dresden, Germany

${ }^{c}$ BIOVIA, Dassault Systèmes Deutschland GmbH, D-51379 Leverkusen, Germany ${ }^{d} U F T$ - Center for Environmental Research and Sustainable Technology, Department of General and Theoretical Ecology, University of Bremen, Leobener Str. 6, D-28359 Bremen, Germany

$\dagger$ Electronic supplementary information (ESI) available. See DOI: 10.1039/ dogc02603d
}

(the only exhaust gas after combustion is water vapor, as opposed to $\mathrm{SO}_{2}, \mathrm{NO}_{x}, \mathrm{CO}, \mathrm{CO}_{2}$ and volatile organic compounds produced from fossil fuels ${ }^{5,7}$ ). The hydrogen used in LOHC systems can be produced either from fossil fuels by steam reforming or by water electrolysis ${ }^{2,8}$ using renewable energy sources (Fig. 1), with the latter considered more attractive. ${ }^{9}$

LOHC systems usually consist of a tandem of organic molecules, one of which is saturated $\left(\mathrm{H}_{2}\right.$-rich, loaded), and the other is unsaturated ( $\mathrm{H}_{2}$-lean, unloaded or spent). The compounds forming the LOHC tandem can be reversibly converted into each other by catalytic hydrogenation (e.g., catalysts $\mathrm{Ru} / \mathrm{Al}_{2} \mathrm{O}_{3}, 10-50$ bar, ${ }^{8} 150{ }^{\circ} \mathrm{C}$ (ref. 10)) of the unsaturated form and dehydrogenation (e.g., catalysts $\mathrm{Pt} / \mathrm{Al}_{2} \mathrm{O}_{3}, 1-5 \mathrm{bar}{ }^{8}$ 130-300 ${ }^{\circ} \mathrm{C}$ (ref. 8, 10 and 11)) of the saturated form (Fig. 1). ${ }^{9}$ The LOHC chemicals are not consumed in the process of energy generation and can be subject to multiple hydrogenation and dehydrogenation cycles, which is very different from fossil fuels. ${ }^{2}$ Due to the similarities in the physicochemical properties of LOHCs to those of fossil fuels, ${ }^{2,3}$ they can be implemented using the existing infrastructure, such as ships, 


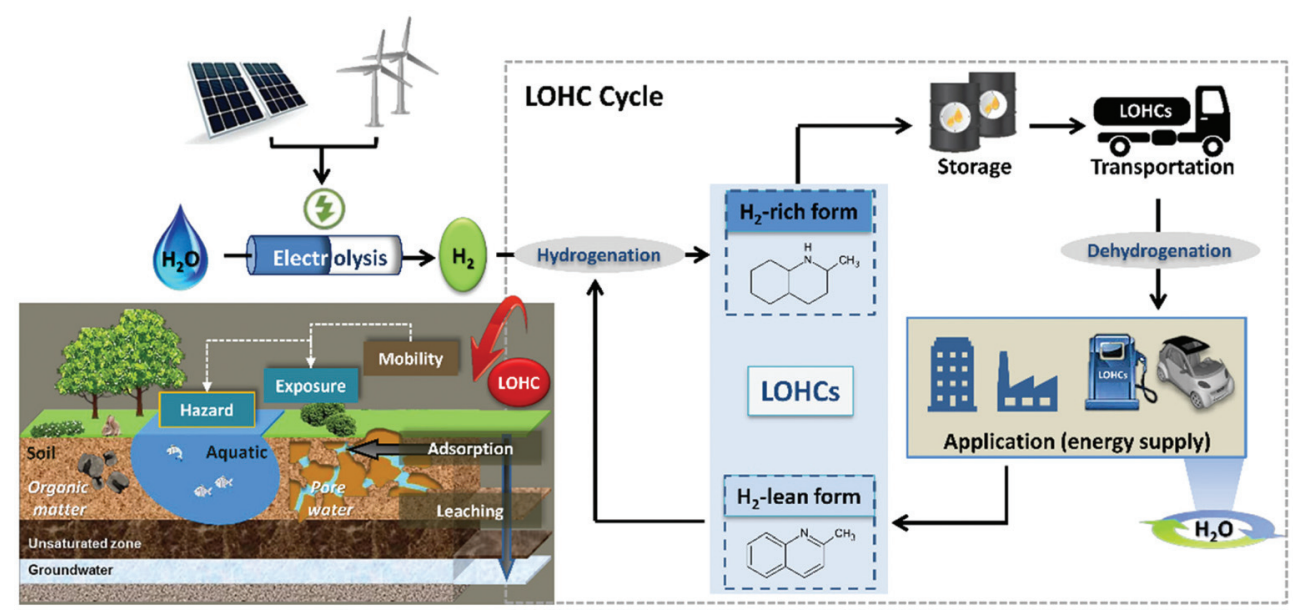

Fig. 1 Distribution of energy in the form of $\mathrm{H}_{2}$ via hydrogenation/dehydrogenation of the LOHC systems in cycles of reaction. LOHCs released into the environment (red arrow) during storage, transportation or uses can undergo different partitioning and redistribution processes, e.g., adsorption and leaching, influencing the exposure and hazards to different extent.

ports, ${ }^{2}$ oil tanks, pipelines, and fuelling stations, ${ }^{1,12}$ that were developed for the transport, distribution and processing of fossil fuels. Use of existing infrastructure is economically attractive due to the lower investment costs $^{3,4}$ and a smooth transition between conventional and LOHC energy systems. ${ }^{1,3}$

Indole,${ }^{3,8}$ quinaldine, ${ }^{3,8}$ and carbazole derivatives, ${ }^{2,3,8,12}$ as well as isomeric mixtures of benzyltoluene or dibenzyltoluene ${ }^{13,14}$ with hydrogen storage capacities ranging from 5 to $7 \mathrm{wt} \%,{ }^{3,4}$ have been recently proposed as the most promising potential candidates. The incorporation of nitrogen into the cyclic ring of LOHCs reduces the dehydrogenation enthalpy $^{3}$ and improves the thermodynamics and kinetics of dehydrogenation. ${ }^{4,8}$ This renders nitrogen-substituted heterocycles particularly promising candidates. ${ }^{3}$ The technological advantages and disadvantages related to particular LOHC candidates, especially in automotive applications, have recently been reported in detail, ${ }^{3,12-16}$ showing that different LOHC systems can be chosen to fulfil requirements of different applications.

The considerable application potential of LOHC systems opens the global markets to this technology and relevant projects and product developments have been initiated in 2011, 2013, and 2014 by Chiyoda Corporation (Japan), Hydrogenious LOHC Technologies (Germany), and Hynertech (China), respectively. ${ }^{17}$ Accordingly, several large-scale pilot applications were launched around the world recently, for instance in Japan (global hydrogen supply chain), ${ }^{18}$ Germany (off-grid power supply ${ }^{8,19}$ and railway transport powered by $\mathrm{LOHC}^{20}$ ), and China (fuel cell bus fuelled by $\mathrm{LOHC}^{21}$ and mobility infrastructure $^{22}$ ). In addition, the prospect of using LOHC technology in underground mining equipment and stationary power applications in South Africa has been recently announced. ${ }^{10}$ Moreover, some LOHC chemicals like benzyltoluene and dibenzyltoluene are already used, although on smaller scale, as heat transfer liquids ${ }^{23}$ while others are components of fossil fuels (e.g., quinaldine or unsubstituted carbazole). ${ }^{24}$
Usually a tank containing approximately $80 \mathrm{~kg}$ of LOHCs is required to achieve a driving range of approx. $700 \mathrm{~km} .{ }^{8}$ The full-scale application of this technology and the complete replacement of fossil fuels would thus require approx. $2 \times 10^{10}$ $3 \times 10^{10}$ tons of LOHCs to be handled, processed, stored and transported to satisfy the current energy demand worldwide. ${ }^{4,11}$ Due to such large volume in application and transport, the consequence of LOHC release (e.g., through leaks and accidental spills during production, transport and fuelling) into the environment should be considered. More specifically, the environmental hazard potential of these chemicals should ideally be known before the technology enters widespread commercial use to assure that the LOHC systems of both the best technological performance and least harm to the environment are chosen. However, experimental data regarding the environmental behaviour (in terms of mobility, adsorption and fate) of the LOHCs are still too scarce to make a reliable assessment.

There are several reasons that make the assessment of environmental impacts of the LOHC chemicals particularly interesting besides the large application scale. Firstly, many LOHC chemicals are organic bases with (predicted) $\mathrm{p} K_{\mathrm{b}}$ (base dissociation constant) values within environmentally relevant range, meaning they will be at least partially positively charged. Ionic and ionisable chemicals are outside the applicability domain of most models designed to predict affinity to soils. $^{25,26}$ Consequently, these models deliver inadequate predictions, sometimes several orders of magnitude different from the measured value. ${ }^{27}$ Secondly, the lack of experimental data for $K_{\text {ow }}$ (n-octanol/water partition coefficient), $D_{\text {ow }}\left(\mathrm{pH}^{-}\right.$ dependent distribution coefficient) or $\mathrm{p} K_{\mathrm{b}}$ that are needed for the models means that these values have to be estimated as well, which additionally increases the uncertainty of prediction. Lastly, our recent studies have indicated that some of the LOHC chemicals investigated here are poorly biodegradable (i.e. potentially persistent) or show considerable 
acute aquatic toxicity ${ }^{11}$ and chronic soil toxicity. ${ }^{28}$ Therefore, their continued release to the environment would lead to increasing concentrations which might adversely affect the biota.

Recently, in addition to Persistent, Bioaccumulative and Toxic (PBT) substances, a new class of substances of high concern was identified by regulatory agencies (German Environment Agency, UBA - Das Umweltbundesamt) namely Persistent, Mobile and Toxic (PMT) substances. ${ }^{29}$ These chemicals are polar and exhibit lower affinities to organic matter and solids in soils and sediments, as a result they might move through aquifers and various natural (e.g., riverbank and soil layers) or artificial (wastewater treatment plant ${ }^{29,30}$ ) barriers, ${ }^{29}$ implying increased probability to enter the water cycle and perhaps even to reach drinking water sources. ${ }^{29}$ Therefore, unlike PBT substances to which biota and humans are primarily exposed via diet, PMT chemicals are likely to exert negative effects via water sources. ${ }^{29}$ The UBA has recently proposed to qualify PMTs as Substances of Very High Concern (SVHC), ${ }^{29,31}$ which need to be treated with "equivalent level of concern" to those listed by REACH (e.g., PBTs) in terms of the direct impacts to human health or the environment ${ }^{29}$ via e.g., drinking water supplies.

Due to the physicochemical properties of LOHCs as well as the types of use, all environmental compartments, i.e. soil, water and air, are likely to be affected. Among these compartments, soil is of particular importance since it usually acts as a barrier and sink for anthropogenically produced organic chemicals. Once in the soil, organic contaminants may undergo various processes, among which adsorption is particularly important in defining their mobility, i.e. how far they can spread from the point of release and what concentrations can be expected in adjacent ground and surface waters. The assessment of the chemicals' affinity to soils is therefore crucial in determining their probability to reach the groundwater and drinking water sources. Adsorption also defines the extent of exposure of soil-dwelling organisms in which uptake is not based on the consumption of soil particles (i.e. porewater is the dominant route of exposure).

The present study therefore aimed to characterise the behaviour of several promising LOHC systems based on: quinaldine, indole, carbazole derivatives (ethylcarbazole, butylcarbazole, propylcarbazole), benzyltoluene and dibenzyltoluene, by investigating their adsorption to and mobility in standard soil. To this end, organic carbon-water partition coefficients $\left(K_{\text {oc }}\right)$ were measured using HPLC, and based on these values LOHC chemicals were assigned to mobility classes. Additionally, the soil-water partition coefficients $\left(K_{\mathrm{d}}\right)$ were measured using batch equilibrium and soil column leaching methods.

\section{Materials and methods}

A detailed description of the chemicals and the experimental procedures is given in the ESI. $\dagger$

\section{Materials}

The LOHC systems tested in the present study, including indoles, quinaldines (Quin), alkylcarbazole derivatives (Cars), benzyltoluenes (marketed as Marotherm LH® - MLH) and dibenzyltoluene (marketed as Marlotherm SH® - MSH) (Table 1), were provided by the research group of Prof. Dr Peter Wasserscheid, Institute of Chemical Reaction Engineering, Friedrich-Alexander University of Erlangen-Nürnberg, Germany. Two batches of standard soil RefeSol 01-A-004 (briefly named soil I and soil II), loamy sand (soil I: $\mathrm{pH}\left(\mathrm{CaCl}_{2}\right)$ $=5.4, \mathrm{C}_{\text {org }} 1.21 \%$, sand $76.7 \%$, silt $17.2 \%$, clay $6.1 \%$; soil II: $\mathrm{pH}$ $\left(\mathrm{CaCl}_{2}\right)=5.3, \mathrm{C}_{\text {org }} 0.80 \%$, same texture as soil I) were ordered from Fraunhofer IME, Schmallenberg, Germany (Table S1 $†$ ). The soils were dried for $24 \mathrm{~h}$ at room temperature and $2.0 \mathrm{~mm}$-sieved before tests. Detailed information on all the materials is available in ESI-S1.†

\section{Determination of $\log K_{\mathrm{oc}}$}

The $\log K_{\mathrm{oc}}$ values of the LOHCs (Table 1) were first predicted by the Conductor-like Screening Model for Realistic Solvation (COSMO-RS, Leverkusen, Germany, see ESI-S2 $\dagger$ ) to estimate the retention times. Subsequently, the $K_{\mathrm{oc}}$ values of the $\mathrm{H}_{2}$-lean and partially hydrogenated LOHC (-ph) chemicals were determined by high-performance liquid chromatography (HPLC) screening following OECD guideline $121 .{ }^{32}$ The $\mathrm{H}_{2}{ }^{-}$ rich forms of the LOHC chemicals were not investigated due to their lack of UV activity. The test procedures in detail showing also the calibration and calculation of $\log K_{\text {oc }}$ are described in ESI-S3. $\dagger$ The LOHCs were then assigned to relative mobility classes based on the $\log K_{\mathrm{oc}}$.

\section{Determination of $\boldsymbol{K}_{\mathrm{d}}$ and adsorption isotherm}

The quinaldine-based LOHC system was chosen as an example for cross-check. It was selected since its components are ionisable within the environmental $\mathrm{pH}$ range (Table 1), suggesting that their partitioning behaviour might not conform to the commonly used models. The adsorption isotherms in soil I were established for five concentrations $(2.5,5.0,10,25$, and $50 \mathrm{mg} \mathrm{L}^{-1}$ ) following the batch equilibrium protocol given by OECD guideline $106 .^{33}$ Two independent tests with triplicates of each concentration were conducted for every compound. Test details are described in ESI-S4. $\dagger$

The quinaldines were extracted using a liquid-liquid extraction and the amount was measured using gas chromatography mass spectrometry (GC/MS) analysis.

The amount of quinaldine adsorbed to the soil was calculated by subtracting the amount remaining in the aqueous phase at equilibration from the amount initially added. The concentrations of the test compounds in the soil phase $\left(q_{\mathrm{e}}\right)$ were plotted against the concentrations in the liquid phase $\left(C_{\mathrm{e}}\right)$, and $K_{\mathrm{d}}$ (batch- $\left.K_{\mathrm{d}}\right)$ was thus calculated as the slope of the linear portion of the adsorption curve. Freundlich model (eqn (1)) was used to fit the experimental data:

$$
\log q_{\mathrm{e}}=\log K_{\mathrm{f}}+1 / n \log C_{\mathrm{e}}
$$


Table 1 Physicochemical properties of the LOHC candidates

\begin{tabular}{|c|c|c|c|c|c|c|c|c|}
\hline LOHC name & Abbreviation & Formula & Chemical structure & $\begin{array}{l}\mathrm{MW} \\
{\left[\mathrm{g} \mathrm{mol}^{-1}\right]}\end{array}$ & $\begin{array}{l}\log S_{\mathrm{W}}{ }^{a} \\
\left(25^{\circ} \mathrm{C}\right) \\
{\left[\mathrm{mg} \mathrm{L}^{-1}\right]}\end{array}$ & $\log K_{\mathrm{ow}}{ }^{a}$ & $\log K_{\mathrm{oc}}{ }^{a}$ & $\begin{array}{l}\text { P. }{ }^{c} \\
{[\%]}\end{array}$ \\
\hline 2-Methyl-quinoline & Quin-2Me & $\mathrm{C}_{10} \mathrm{H}_{9} \mathrm{~N}$ & & 143.2 & 3.95 & 2.45 & 2.18 & $\begin{array}{l}40 \text { or } \\
36\end{array}$ \\
\hline Tetrahydro-2-methyl-quinoline & Quin-2Me-ph & $\mathrm{C}_{10} \mathrm{H}_{13} \mathrm{~N}$ & & 147.2 & 2.66 & 3.04 & 2.48 & $\begin{array}{l}26 \text { or } \\
23\end{array}$ \\
\hline Decahydro-2-methyl-quinoline ${ }^{b}$ & $\begin{array}{l}\text { Quin-2Me- } \\
\text { H10 }\end{array}$ & $\mathrm{C}_{10} \mathrm{H}_{19} \mathrm{~N}$ & & 153.3 & 3.86 & 3.25 & 2.53 & 100 \\
\hline Indole & Indole & $\mathrm{C}_{8} \mathrm{H}_{7} \mathrm{~N}$ & & 117.2 & 4.05 & 2.32 & 2.21 & n.a. \\
\hline Indoline & Indoline & $\mathrm{C}_{8} \mathrm{H}_{9} \mathrm{~N}$ & & 119.2 & 3.71 & 2.04 & 1.94 & $\begin{array}{l}16 \text { or } \\
14\end{array}$ \\
\hline 9-Ethyl-9H-carbazole & Car-2 & $\mathrm{C}_{14} \mathrm{H}_{13} \mathrm{~N}$ & & 195.3 & 1.09 & 4.42 & 3.36 & n.a. \\
\hline 9-Ethyl-hexahydro-carbazole ${ }^{b}$ & Car-2-ph & $\mathrm{C}_{14} \mathrm{H}_{19} \mathrm{~N}$ & & 201.3 & 0.97 & 4.60 & 3.08 & $\begin{array}{l}20 \text { or } \\
17\end{array}$ \\
\hline 9-Ethyl-octahydro-carbazole & & $\mathrm{C}_{14} \mathrm{H}_{21} \mathrm{~N}$ & & 203.3 & 0.36 & 5.19 & 3.26 & n.a. \\
\hline 9-Ethyl-dodecahydro-carbazole & Car-2-H12 & $\mathrm{C}_{14} \mathrm{H}_{25} \mathrm{~N}$ & & 207.4 & 1.91 & n.a. & n.a. & 100 \\
\hline 9-Propyl-9H-carbazole & Car-3 & $\mathrm{C}_{15} \mathrm{H}_{15} \mathrm{~N}$ & & 209.3 & 0.54 & 4.96 & 3.61 & n.a. \\
\hline 9-Propyl-hexahydro-carbazole ${ }^{b}$ & Car-3-ph & $\mathrm{C}_{15} \mathrm{H}_{21} \mathrm{~N}$ & & 215.3 & 0.41 & 5.16 & 3.36 & $\begin{array}{l}27 \text { or } \\
23\end{array}$ \\
\hline 9-Propyl-octahydro-carbazole & & $\mathrm{C}_{15} \mathrm{H}_{23} \mathrm{~N}$ & & 217.4 & -0.19 & 5.72 & 3.50 & n.a. \\
\hline 9-Propyl-dodecahydro-carbazole & Car-3-H12 & $\mathrm{C}_{15} \mathrm{H}_{27} \mathrm{~N}$ & & 221.4 & 1.40 & n.a. & n.a. & 100 \\
\hline 9-Butyl-9H-carbazole & Car-4 & $\mathrm{C}_{16} \mathrm{H}_{17} \mathrm{~N}$ & & 223.3 & -0.001 & 5.50 & 3.89 & n.a. \\
\hline
\end{tabular}


Table 1 (Contd.)

\begin{tabular}{|c|c|c|c|c|c|c|c|c|}
\hline LOHC name & Abbreviation & Formula & Chemical structure & $\begin{array}{l}\text { MW } \\
{\left[\mathrm{g} \mathrm{mol}^{-1}\right]}\end{array}$ & $\begin{array}{l}\log S_{\mathrm{w}}{ }^{a} \\
\left(25^{\circ} \mathrm{C}\right) \\
{\left[\mathrm{mg} \mathrm{L}^{-1}\right]}\end{array}$ & $\log K_{\mathrm{ow}}{ }^{a}$ & $\log K_{\mathrm{oc}}{ }^{a}$ & $\begin{array}{l}\text { P. }{ }^{c} \\
{[\%]}\end{array}$ \\
\hline 9-Butyl-hexahydro-carbazole ${ }^{b}$ & Car-4-ph & $\mathrm{C}_{16} \mathrm{H}_{23} \mathrm{~N}$ & & 229.4 & -0.04 & 5.58 & 3.62 & $\begin{array}{l}27 \text { or } \\
24\end{array}$ \\
\hline 9-Butyl-octahydro-carbazole & & $\mathrm{C}_{16} \mathrm{H}_{25} \mathrm{~N}$ & & 231.4 & -0.77 & 6.27 & 3.79 & n.a. \\
\hline 9-Butyl-dodecahydro-carbazole & Car-4-H12 & $\mathrm{C}_{16} \mathrm{H}_{29} \mathrm{~N}$ & & 235.4 & 0.89 & n.a. & n.a. & 100 \\
\hline Benzyltoluene & $\mathrm{MLH}$ & $\mathrm{C}_{14} \mathrm{H}_{14}$ & & 182.3 & 0.69 & 4.78 & 3.34 & n.a. \\
\hline $\begin{array}{l}\text { Benzyltoluene (partially } \\
\text { hydrogenated) }\end{array}$ & MLH-ph & $\mathrm{C}_{14} \mathrm{H}_{20}$ & & 188.3 & 0.02 & 5.46 & 3.65 & n.a. \\
\hline Dibenzyltoluene $^{b}$ & $\mathrm{MSH}$ & $\mathrm{C}_{21} \mathrm{H}_{20}$ & & 272.4 & -1.37 & 6.84 & 4.52 & n.a. \\
\hline
\end{tabular}

"P." indicates percentage of protonation; "n.a." indicates values are out of the environmentally relevant range. ${ }^{a} S_{\mathrm{w}}$ : water solubility at $25{ }^{\circ} \mathrm{C}$, $\log K_{\text {ow }}: n$-octanol/water partition coefficient, $\log K_{\text {oc }}$ : soil organic carbon-water partition coefficient. Values were predicted using in silico model COSMO-RS for the neutral forms of the compound (see ESI-S2 $\dagger$ ). ${ }^{b}$ Mean values of cis and trans isomers. ${ }^{c}$ Estimated at the pH 5.3 and pH 5.4 (the $\mathrm{pH}$ of test soil I and II) using MarvinSketch. ${ }^{35}$

where the Freundlich constant $\left(K_{\mathrm{f}}\right)$ and the Freundlich exponent $1 / n$ were obtained. The coefficient of determination $\left(R^{2}\right)$ was also calculated to describe the goodness of fit.

\section{Leaching in soil columns}

The leaching of quinaldines in soil II was tested in soil columns according to OECD guideline $312 .{ }^{34}$ The column design and all the details on the soil column preparation and quinaldine spiking are in ESI-S5. $\dagger$ Additionally, atrazine was used as the reference compound (Table S2 $\dagger$ ) and two columns containing only atrazine were run for $648 \mathrm{~h}$. The total concentrations of the LOHC and atrazine in the soil column were 100 and $20 \mathrm{mg} \mathrm{kg}^{-1} \mathrm{dw}$ soil, respectively. Artificial rain $(0.01 \mathrm{M}$ $\mathrm{CaCl}_{2}$ ) was simulated by dropwise addition of water to the top of the column with the aid of a peristaltic pump (Spetec, Perimax 12, Erding, Germany) at a flow rate of $0.108 \mathrm{~mL} \mathrm{~min}^{-1}$ for $172 \mathrm{~h}$ (Quin-2Me-H10), $648 \mathrm{~h}$ (Quin-2Me) or $720 \mathrm{~h}$ (Quin$2 \mathrm{Me}$-ph). The leachates were collected from the bottom of the column every 24 or $48 \mathrm{~h}$ and passed through filters made of glass wool packed in Pasteur pipettes. Two independent leaching tests were performed for each compound, with two replicates (columns) performed for each test. The compounds in the leachates were extracted by liquid-liquid extraction and analysed by GC/MS. The amount of the test compound in the leachate was calculated as percentage of the total mass (mass\%) that was originally added and plotted against the multiples of the pore volume (PV). The breakthrough was determined as the PV point at which the substance first appeared at the outlet.

Another set of $K_{\mathrm{d}}$ values (column- $K_{\mathrm{d}}$ ) was thus determined from the column leaching experiments according to the method proposed by the Environmental Protection Agency (EPA). ${ }^{36}$ Here, the $K_{\mathrm{d}}$ values were directly calculated from the retardation factor $\left(R_{\mathrm{f}}\right)$ and factors related to the soil properties ( $n$, total porosity; $\rho_{\mathrm{b}}$, bulk density) using the equation (eqn (2)):

$$
K_{\mathrm{d}}=\left[\left(R_{\mathrm{f}}-1\right) \times n\right] / \rho_{\mathrm{b}}
$$

The details on the determination of the parameters for the calculation of $K_{\mathrm{d}}$ are available in ESI-S5. $\dagger$

\section{Liquid-liquid extraction and GC/MS analysis}

The concentrations of quinaldines were determined via liquid-liquid extraction (see ESI-S6 $\dagger$ ) followed by GC/MS analysis on a gas chromatograph (HP® GC system 6890N) equipped with a mass selective detector (HP® MS 5973, Agilent, Waldbronn, Germany). Further details of the setup and calibration parameters are given in ESI-S7.† 


\section{Statistical analysis}

Regression analysis was performed for the comparison between COSMO-RS and HPLC methods in terms of $K_{\mathrm{oc}}$ values and for the evaluation of adsorption isotherms. Significance of difference between two data sets (i.e. the $K_{\mathrm{d}}$ values of $\mathrm{H}_{2}$-rich and $\mathrm{H}_{2}$-lean forms of the quinaldines that were obtained in adsorption batch test) were analysed by generalised linear models using $\mathrm{R}$ (i 3864.0.0). ${ }^{37} P>0.05$ was considered not significant.

\section{Results}

\section{Mobility screening}

As a first step we used in silico model COSMO-RS to predict $\log K_{\mathrm{ow}}$ and $\log K_{\mathrm{oc}}$ of all tested compounds (Table 1). The $\log K_{\mathrm{oc}}$ values were then measured using cyanopropyl HPLC column. ${ }^{32}$ This HPLC column showed an excellent performance and comparability of $\log K_{\mathrm{oc}}$ values with those obtained using batch test for a wide variety of both polar and non-polar as well as ionisable and neutral compounds. ${ }^{39}$ The $\log K_{\mathrm{oc}}$ values determined for LOHC chemicals ranged from 1.17 to 5.41 (Table 2). The partially hydrogenated forms of the alkylcarbazoles, MLHs and MSH were found to exist as technical mixtures containing at least two components (Table S3†); therefore, the mean retention time of all the components was used to calculate $K_{\mathrm{oc}}$. The LOHCs were assigned to mobility classes according to their $\log K_{\mathrm{oc}}$ values and McCall's scale of mobility in soil. ${ }^{38}$ According to this scale, indoline, which had the lowest $\log K_{\mathrm{oc}}$, was classified as highly mobile in soils (class I: $\left.\log K_{\mathrm{oc}} 1.70-2.18\right)$. Quin-2Me, Quin-2Me-ph and indole fell into the "moderately mobile" category (class II: $\log K_{\mathrm{oc}}$ 2.18-2.70). The remaining compounds were characterised by notably higher $\log K_{\mathrm{oc}}$ values, which increased in the following order: $\mathrm{MLH}<$ Car-2 < Car-2-ph < Car-3 < Car-3-ph $<$ Car-4 $\approx$ Car-4-ph $<\mathrm{MSH}<\mathrm{MLH}-\mathrm{ph}$. Thus, these compounds were assigned to the lowest mobility class (class V: $\log K_{\mathrm{oc}}>3.70$ ) and labelled "immobile". Moreover, the carbazoles containing extended alkyl chains tended to have higher $\log K_{\mathrm{oc}}$ values and lower mobility. The $\log K_{\mathrm{oc}}$ values determined using HPLC method correlated well with those predicted by COSMO-RS $\left(R^{2}=0.92\right.$, Fig. $\left.\mathrm{S} 1 \dagger\right)$.

\section{$K_{\mathrm{d}}$ and adsorption isotherms of the quinaldine LOHC system}

The batch- $K_{\mathrm{d}}$ of the quinaldine-based LOHC system followed the order: Quin-2Me-ph (6.57 $\left.\mathrm{mL} \mathrm{g}^{-1}\right)>$ Quin-2Me-H10 $\left(2.42 \mathrm{~mL} \mathrm{~g}^{-1}\right) \geq$ Quin-2Me $\left(2.03 \mathrm{~mL} \mathrm{~g}^{-1}\right)$ (Table 3), in which a difference of a factor of 2 to 3 existed between the partition coefficients of the first and the other two compounds, and the batch- $K_{\mathrm{d}}$ of the latter two compounds were very similar (no significant difference, with $p=0.77$ ). The shapes of the adsorption isotherms (Fig. 2) provided some comparative insights into the interaction potentials of the three quinaldines in this test system. The isotherm of Quin-2Me and Quin-2Me-H10 had generally similar and lower slopes, whereas the isotherm of Quin-2Me-ph was characterised by a greater slope than the other two.

Furthermore, adsorption isotherms were fitted using Freundlich model $\left(R^{2}=0.95-0.97\right)$ (Table 4). The highest adsorption coefficient $\left(K_{\mathrm{f}}\right)$ estimated by the model was found for Quin-2Me-ph $\left(9.20 \mathrm{~mL} \mathrm{~g}^{-1}\right)$, which was followed by Quin2Me-H10 (5.72 $\left.\mathrm{mL}^{-1}\right)$ and Quin-2Me (4.19 $\mathrm{mL}^{-1}$ ). Comparatively, low values of Freundlich parameter $(1 / n)$ were observed for Quin-2Me and Quin-2Me-H10 while higher 1/n approaching unity was found for Quin-2Me-ph (0.96, Table 4).

Table 3 Summarised $K_{\mathrm{d}}, \log K_{\mathrm{oc}}, \log D$, and $\mathrm{p} K_{\mathrm{b}}$ values of the quinaldines

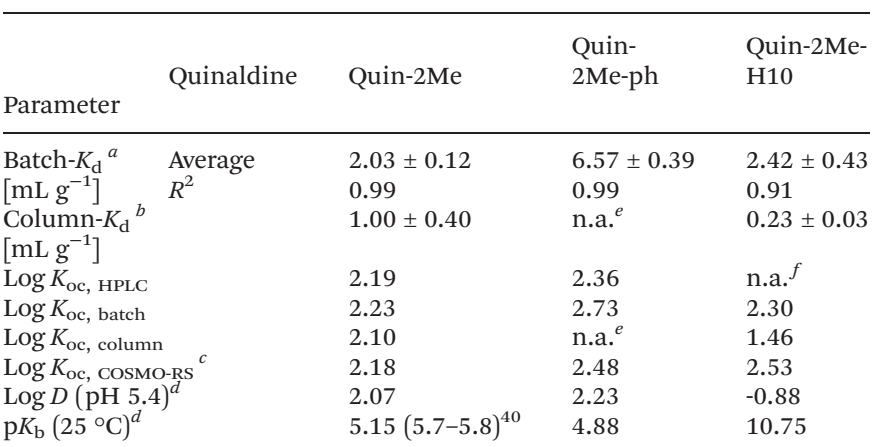

${ }^{a}$ Determined in the adsorption batch equilibrium experiment in soil I $(n=6, \pm \mathrm{SD}) .{ }^{b}$ Determined in the soil column leaching test in soil II $(n=4$, \pm SD). ${ }^{c}$ Predicted using COSMO-RS. ${ }^{d}$ Estimated using MarvinSketch. ${ }^{35}$ ${ }^{e}$ Could not be calculated due to strong retention of the substance in soil column. ${ }^{f}$ Not available in HPLC due to the lack of UV activity of the substance.

Table $2 \log K_{\mathrm{oc}}(n=3, \pm \mathrm{SD})$ determined by HPLC screening and the classification of mobility according to McCall's soil mobility scale ${ }^{38}$

\begin{tabular}{|c|c|c|c|c|c|c|c|c|c|}
\hline LOHC & \multicolumn{4}{|c|}{ Indoline } & \multicolumn{2}{|c|}{ Quin-2Me } & \multicolumn{2}{|c|}{ Quin-2Me-ph } & Indole \\
\hline $\begin{array}{l}\log K_{\mathrm{oc}} \\
\text { Mobility }\end{array}$ & \multicolumn{4}{|c|}{$\begin{array}{l}1.71 \pm 0.01 \\
\text { Highly mobile (class I: } \log K_{\mathrm{oc}} 1.70-2.18 \text { ) }\end{array}$} & \multicolumn{4}{|c|}{$\begin{array}{lc}2.19 \pm 0.02 & 2.36 \pm 0.01 \\
\left.\text { Moderately mobile (class II: } \log K_{\mathrm{oc}} 2.18-2.70\right)\end{array}$} & \multirow{2}{*}{$\frac{2.36 \pm 0.01}{\text { MLH-ph }}$} \\
\hline LOHC & MLH & Car-2 & Car-2-ph ${ }^{a}$ & Car-3 & Car-3-ph ${ }^{a}$ & Car-4 & Car-4-ph ${ }^{a}$ & $\mathrm{MSH}^{a}$ & \\
\hline $\begin{array}{l}\log K_{\mathrm{oc}} \\
\text { Mobility }\end{array}$ & $\begin{array}{l}3.85 \pm 0.07 \\
\text { Immobile }(\end{array}$ & $\begin{array}{l}4.27 \pm 0.01 \\
\text { Ss V: } \log K_{\mathrm{oc}}\end{array}$ & $\begin{array}{l}4.31 \pm 0.06 \\
70)\end{array}$ & $4.61 \pm 0.05$ & $4.63 \pm 0.05$ & $5.01 \pm 0.01$ & $5.01 \pm 0.07$ & $5.38 \pm 0.22$ & $5.41 \pm 0.23$ \\
\hline
\end{tabular}

${ }^{a}$ Mean value \pm SD of the components (include cis and trans isomers) in mixtures. 

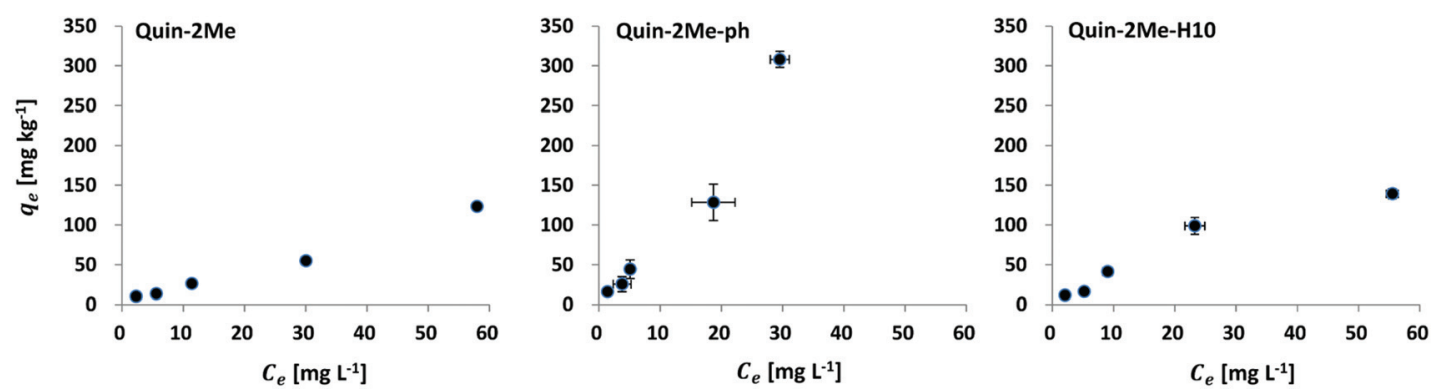

Fig. 2 Adsorption isotherms $\left(n=6, \pm\right.$ SD) of the quinaldines in soil I. The concentrations of the quinaldines in the soil phase ( $\left.q_{\mathrm{e}}\right)$ are plotted as the function of the concentrations in the liquid phase $\left(C_{\mathrm{e}}\right)$.

Table 4 Parameters of the Freundlich model for quinaldines

\begin{tabular}{lllr}
\hline Quinaldine & Model & $K_{\mathrm{f}}\left[\mathrm{mL} \mathrm{g}^{-1}\right]$ & $1 / n$ \\
\hline Quin-2Me & $\log q_{\mathrm{e}}=0.6218+0.7875 \log C_{\mathrm{e}}$ & 4.19 & 0.79 \\
Quin-2Me-ph & $\log q_{\mathrm{e}}=0.9637+0.9629 \log C_{\mathrm{e}}$ & 9.20 & 0.96 \\
Quin-2Me-H10 & $\log q_{\mathrm{e}}=0.7574+0.8296 \log C_{\mathrm{e}}$ & 5.72 & 0.97 \\
& & & 0.96 \\
& & & 0.95
\end{tabular}

This signifies that while the adsorption of the two former compounds is decreasing with concentration, the adsorption of Quin-2Me-ph is increasing almost linearly with concentration showing nearly no sign of approaching saturation. This is concurrent with the shape of the isotherms themselves (Fig. 2).

Since $K_{\mathrm{oc}}$ is the soil-water partition coefficient normalised to the amount of soil organic matter according to the empirical equation $K_{\mathrm{oc}}=K_{\mathrm{d}} / f_{\mathrm{oc}}, K_{\mathrm{oc}}$ can be easily calculated from the measured batch- $K_{\mathrm{d}}$ values in soil I, giving $\log K_{\mathrm{oc}}$, batch values of 2.23, 2.73, and 2.30 for Quin-2Me, Quin-2Me-ph, and Quin2Me-H10, respectively (Table 3 ).

\section{Leaching of quinaldines in soil columns}

Breakthrough was achieved the fastest (approx. at $2 \mathrm{PV}$ ) for Quin-2Me-H10 (Fig. 3C and S2C $\dagger$ ), with approximately $65 \%$ of the total mass ultimately collected in the leachate. The breakthrough of Quin-2Me (Fig. 3A and $\mathrm{S} 2 \mathrm{~A} \dagger$ ) occurred later than that of Quin-2Me-H10 with a lag of approx. 7-9 PV, and approximately $45 \%-60 \%$ of this compound was ultimately collected in the effluent of the column. Quin-2Me-ph behaved very differently from the other quinaldines, with more than $99 \%$ of the total spiked mass retained on the column at the end of the test (Fig. 3B and $\mathrm{S} 2 \mathrm{~B} \dagger$ ). Atrazine, which was used as the reference compound and run either alone in a separate column (Fig. S3A and S4A $\dagger$ ) or in the same column with the quinaldines (Fig. S3B-D and S4B-D $\dagger$ ), showed a relatively constant leaching behaviour with breakthrough occurring at 4-6 PV (or approximately 48-72 h), and more than 90\% was collected in the leachate at the end of the test.

The column- $K_{\mathrm{d}}$ values calculated according to the $\mathrm{EPA}^{36}$ yielded values of $1.00 \mathrm{~mL} \mathrm{~g}^{-1}$ and $0.23 \mathrm{~mL} \mathrm{~g}^{-1}$ for Quin-2Me and Quin-2Me-H10, respectively (Table 3). The $K_{\mathrm{d}}$ obtained for Quin-2Me in the column experiment was within a factor of 2 compared to the value measured in the batch experiment.

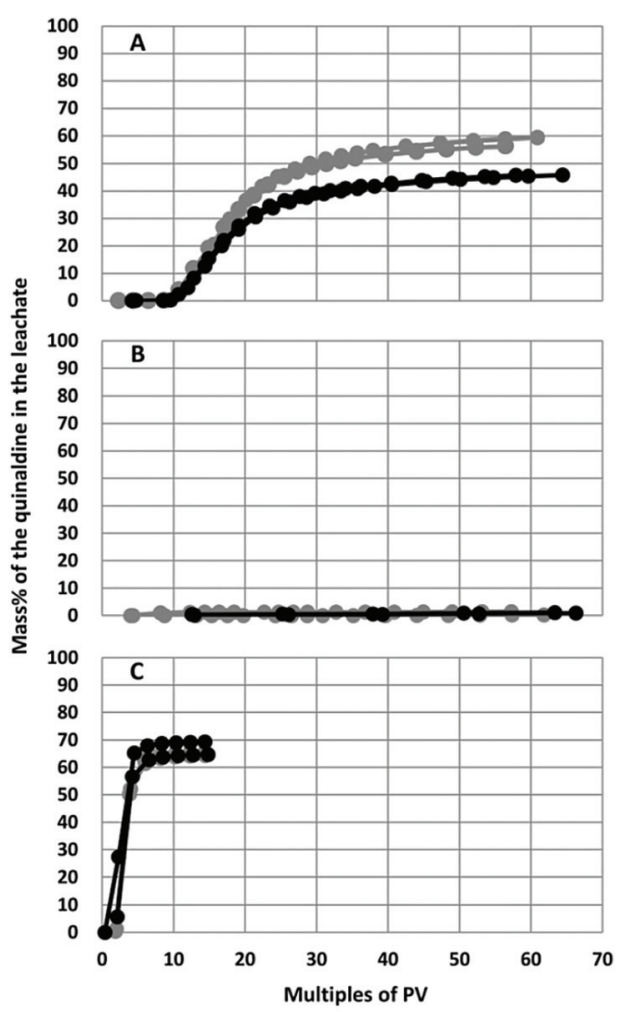

Fig. 3 Breakthrough curves for Quin-2Me (A), Quin-2Me-ph (B) and Quin-2Me-H10 (C) in two independent experiments (grey and black), each with two columns packed with soil II. "PV": pore volume.

Quin-2Me-ph was strongly retained in the column, therefore no column- $K_{\mathrm{d}}$ value was calculated. This suggested however much higher affinity to soil than could have been expected based on batch- $K_{\mathrm{d}}$ and as compared to other two compounds. 
On the contrary, the column- $K_{\mathrm{d}}$ for Quin-2Me-H10 was an order of magnitude lower than that obtained in the batch experiment. Additionally, using the empirical equation for $K_{\mathrm{oc}}$,

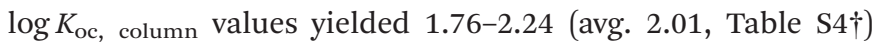
were calculated for atrazine which were very close to literature values of 1.92. The $\log K_{\mathrm{oc}}$, column values for Quin-2Me and Quin-2Me-H10 was calculated to be 2.10 and 1.46 , respectively (Table 3).

\section{Discussion}

\section{Interaction of LOHCs with soil}

In this study, we characterised the adsorption and mobility of LOHCs taking into account different levels of hydrogen saturation.

It is often assumed that the hydrophobic interactions with soil organic matter are the main forces driving adsorption of organic compounds to soils. For that reason, if experimentally determined $K_{\mathrm{oc}}$ values are not available, $K_{\mathrm{ow}}$ is often used to predict parameters defining affinity to soils e.g., $K_{\mathrm{oc}}$. The $\log K_{\mathrm{oc}}$ values obtained using HPLC showed a good correlation with the COSMO-RS-predicted $\log K_{\text {ow }}$ values $\left(R^{2}=0.94\right.$, Fig. $55 \dagger)$. Yet the $K_{\text {ow }}$ seems to underestimate the $K_{\text {oc }}$ value obtained by HPLC, especially for more hydrophobic compounds with a $\log K_{\mathrm{ow}}>3.0$ (Fig. S5 $\dagger$ ).

The $\log K_{\mathrm{oc}}$ values for the LOHC candidates and some of their partially hydrogenated forms measured using HPLC spanned five orders of magnitude (1.71-5.41) (Table 2). The potential mobility of these compounds in soil, ranged from highly mobile to immobile, proving that they have vastly different potentials to contaminate drinking water sources. Partitioning into soil organic matter plays an important role in the retention of many chemicals in soil ${ }^{41-43}$ and the mobility decreases with increasing $K_{\mathrm{oc}} \cdot{ }^{44,45}$ The compounds with the highest $K_{\mathrm{oc}}$ values are more likely to be retained and accumulated at the soil surface where they were released. Therefore, it seems that indoline, Quin-2Me, Quin-2Me-ph and indole would likely be transported further and deeper crossing natural barriers such as soil layers and aquifers than the carbazole derivatives, MLHs and MSH.

In spite of the role of organic matter in controlling chemicals' adsorption in soils, among the test set are compounds that can be charged to a different extent depending on the $\mathrm{pH}$ of the solution (see Table 1 for potential protonation and Table 3 for $\mathrm{p} K_{\mathrm{b}}$ values). Hydrophobic interactions with soil organic carbon dominating the sorption is often true for neutral organic compounds but might not be the case for ionisable compounds like quinaldine derivatives. ${ }^{46}$ Ionisation influences not only the compounds' hydrophobicity but also the ability to interact with soil via electrostatic interactions. This type of interaction is not present in a cyanopropyl HPLC column that is recommended for estimation of $K_{\mathrm{oc}}$ according to OECD guideline. ${ }^{32}$ It was also reported that for permanently charged or ionisable compounds their affinity to soils may be largely underestimated by $K_{\mathrm{ow}}{ }^{25}$ Additionally, the degree of saturation of cyclic rings also influences the ability to interact through pi-pi interactions ${ }^{47,48}$ between aromatic rings present in the solute and those present in soil organic matter. We therefore chose a quinaldine-based system to investigate in more detail on how these structural differences will influence the affinity to model soils. To that end the obtained $K_{\mathrm{d}}$ values in the batch equilibrium and column leaching tests were recalculated into $K_{\mathrm{oc}}$ to provide basis for comparisons based on the amount of organic matter present in model soils (Table 3). As we progressed from the least (in silico model) to the more complex and realistic scenario (soil columns) for assessing soil affinity a markable difference in the behaviour of the three members of quinaldine-based LOHC systems became apparent.

For Quin-2Me, the $K_{\text {oc }}$ obtained using modelling (COSMO-RS) and different experimental methods (HPLC, batch and column) were similar (Table 3), with the $\log K_{\mathrm{oc}}$ values ranging from $2.10\left(\log K_{\mathrm{oc}}\right.$, column $)$ to $2.23\left(\log K_{\mathrm{oc}}\right.$, batch $)$ thus Quin-2Me can be classified as "highly mobile" (column leaching) to "moderately mobile" (batch test). ${ }^{38}$ For the saturated form, Quin-2Me-H10, more significant difference in $K_{\mathrm{oc}}$ values (of nearly an order of magnitude) was observed with the $\log K_{\mathrm{oc}}$, column apparently lower than the $\log K_{\mathrm{oc}}$, batch (i.e. $1.46 v$ s. 2.30) implying that the compound's mobility ranges from "very high" $\left(\log K_{\mathrm{oc}}<1.7\right)$ to "moderate". ${ }^{38}$ In other words, the fully saturated quinaldine (Quin-2Me-H10) might be more mobile than could have been expected based on $K_{\mathrm{oc}}$ values predicted by COSMO-RS or obtained experimentally in the batch test system. Quin-2Me-ph was retained strongly in the soil column with less than $1 \%$ of the spiked mass being leached out. Quin-2Me-ph thus seems to be rather "immobile" in soil which was quite unexpected taking into account its rather low predicted and measured $K_{\mathrm{oc}}$ values obtained in HPLC and batch systems.

It is noteworthy that soil in the environment is highly heterogeneous. Large variation of soil composition, from texture to minerals to varied quantity and quality of organic carbon, has to be taken into consideration. In other words, adsorption and mobility of the LOHCs and their accessibility to organisms can vary according to local soil ${ }^{49,50}$ and climatic conditions. $^{51}$

\section{Mechanistic insight into the interaction of quinaldines with soil}

All three quinaldines are organic bases and can be present either in their neutral or protonated forms ${ }^{45,52,53}$ depending on their $\mathrm{p} K_{\mathrm{b}}$ values (Table 3 ) and the $\mathrm{pH}$ of the surroundings. The ionised fractions of the quinaldines, at the $\mathrm{pH}$ values of the tests ( $\mathrm{pH} 5.3$ and 5.4), are in the order following Quin2 Me-ph $(23 \%-26 \%)<$ Quin-2Me $(36 \%-40 \%$ or $66 \%-75 \%) \ll$ Quin-2Me-H10 (100\%) (Table 1). Models available so far perform poorly in describing adsorption of organic ions. This is mostly due to the fact that they usually neglect the interaction potentials of the ionised fraction by assuming that only the neutral portion of the compound is interacting with soil through hydrophobic interactions. Nevertheless, especially organic cations are able to interact strongly with soils. The 
exact molecular mechanisms of their sorption is still elusive but ion-exchange was recognised as one most important interaction. ${ }^{26}$ Droge et al. have recently proposed a model describing adsorption of organic bases (carrying positive charge at test $\mathrm{pH}$ ) to soil taking into account both hydrophobic interactions with soil organic matter (SOM) as well as ion exchange interactions with both clay and SOM fractions. ${ }^{26}$ Applying this modelling frame to our test system shows that despite extensive protonation of the test compounds we should be expecting sorption dominated by hydrophobic interactions. This is due to the fact that both model soils have low CEC (cationexchange capacity) values (Table $\mathrm{S} 1 \dagger$ ), therefore, the contribution of ion-exchange mechanism could be low. This shows that the soil affinity of these ionic compounds cannot be predicted easily and there is a need for better predictive models with applicability domain covering ionic and ionisable compounds.

Although the column leaching experiment was not performed for the other potentially ionisable LOHC compounds in this study, i.e. indoline and alkylcarbazoles, it is probable that their mobility in soils would also deviate from the $K_{\mathrm{oc}}$ obtained using HPLC. Further confirmation of the affinities of these compounds by batch equilibrium and leaching experiments is recommended if these compounds were to be implemented as LOHCs on larger scale.

\section{Estimating and measuring soil affinity - method comparison}

Three typical methods for determining the adsorption of organic contaminants in soils were applied in this study. The HPLC screening method is the least complex, but the assumption that it adequately represents the potential for interaction with the soil was not supported.

Both column leaching and batch equilibrium tests are commonly conducted to evaluate sorption. The duration of the batch equilibrium test is much shorter than that of the column test, especially when investigating strongly adsorbing substrates (such as Quin-2Me-ph in this study). ${ }^{54}$ Moreover, due to efficient mixing, the adsorption equilibrium is generally achieved faster in the batch equilibrium test because macroscopic mass transfer is not hindered. ${ }^{54}$ Therefore, the batch equilibrium test is often treated as the "worst case scenario". 54 However, the mobility (leachability) in soils can be underestimated by the batch equilibrium test, ${ }^{55}$ as what has been shown here particularly for Quin-2Me-H10. Column leaching represents a dynamic system that is supposed to simulate the downward movement of chemicals through soil. ${ }^{54}$ Although the column experiment is more time-consuming, it provides better simulation of the water flow through the porous soil profile due to a more realistic solid-to-liquid ratio. ${ }^{54}$ Processes that occur in nature, such as particle-associated transport, ${ }^{44}$ are also accounted for in column leaching tests. ${ }^{54}$ In such a test, the adsorption equilibrium is not necessarily achieved in the dynamic process, even at the point of breakthrough, ${ }^{54}$ due to insufficient mixing and the adsorption/desorption processes of various, often competing, ions. ${ }^{54,56}$ In addition, column leaching test could provide more information for the assess- ment of the potential for groundwater contamination, which can eventually be correlated to the risk of human exposure via drinking water or contaminated crops. ${ }^{44}$

The concentration used to spike the soil columns in the study was $100 \mathrm{mg} \mathrm{kg}^{-1}$ being the worst-case scenario, which might occur in the environment only through heavy contamination resulting from accidental spills. However, the localised leakage or spillage of these compounds is possible since they may eventually be produced and transported on a large scale and handled by citizens in the same way fossil fuels currently are.

\section{Assessment of persistence, mobility and toxicity}

Recently compounds that are mobile in soils and therefore are able to reach surface water, groundwater or even drinking water are causing increasing concern and may be a subject of regulatory actions in the future. Since there is a concern that some LOHCs possess traits of PMT substances we have performed a PMT-screening using recently proposed cut-off values. ${ }^{29,57,58}$ We have adapted these values to the data that are available for LOHCs, which means in most cases we have used screening-level data. This resulted in following threshold values: (a) $\log K_{\mathrm{oc}}<4.0$ for classification as mobile (M), (b) classification into aquatic toxicity acute category 1 or terrestrial toxicity category 1 for fulfilling the "toxic" criterion (T), and (c) less than $20 \%$ biodegradation in ready biodegradability test for classification as persistent $(\mathrm{P})$. Based on results gathered in this study two components of the quinaldine-based LOHC system (i.e. Quin-2Me and Quin-2Me-H10), indole-based LOHC system (indoline and indole) and $\mathrm{MLH}$ fulfil the ' $\mathrm{M}$ ' criterion (Table 5). The rather low affinity of these compounds to soils indicates a risk of groundwater contamination, especially for Quin-2Me-H10, which is considered "very mobile". All the other compounds are expected to be retained in soil to higher extent and therefore present a lower risk towards groundwater contaminations.

In our previous studies we have shown that Quin-2Me-H10 and Quin-2Me-ph are resistant to biodegradation in ready biodegradability test whereas Quin-2Me is biodegradable to high extent (i.e. not persistent) ${ }^{11}$ (Table 5). This warrants classification of the two former substances as ' $\mathrm{P}$ ' and the latter as 'not P'. Additionally, all $\mathrm{H}_{2}$-lean and $\mathrm{H}_{2}$-rich carbazole derivatives showed no degradation in ready biodegradability test (partially hydrogenated forms were not tested) and were therefore classified as 'P' (Table 5). ${ }^{11}$ On the contrary, $\mathrm{H}_{2}$-lean forms of $\mathrm{MLH}$ and $\mathrm{MSH}$ were significantly degraded in that test system and classified as 'not P' (unpublished results). Indole was shown to be susceptible to biodegradation ${ }^{59}$ and was assessed as readily biodegradable.

Furthermore, low to moderate toxicity of the three quinaldines as well as $\mathrm{H}_{2}$-rich forms of alkylcarbazoles was observed, showing the effects categorised as "acute 2" or "acute 3 " in aquatic $^{11}$ and "harmful" in terrestrial ${ }^{28}$ organisms - none of which fulfils the ' $T$ ' criterion in current 'PMT' assessment approach (Table 5). ${ }^{29,57,58}$ Based on this screening-level data Quin-2Me-H10 would be considered potentially "PM" (persist- 
Table 5 Colour scheme showing the assessment of persistence (P), mobility (M), and toxicity (T) of LOHC chemicals compared to diesel oil

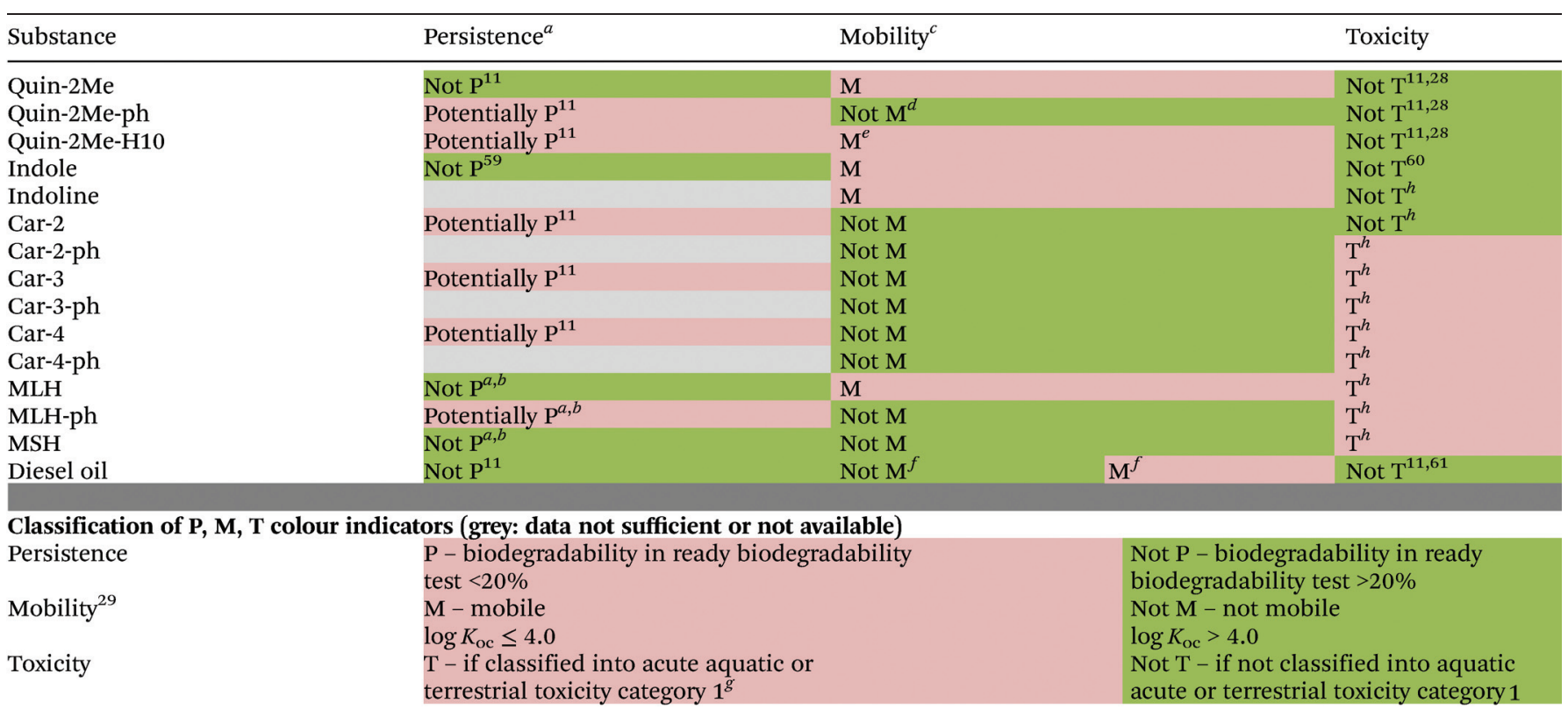

${ }^{a}$ Determined using ready biodegradability test according to OECD $301 \mathrm{~F} .{ }^{11}{ }^{b}$ Unpublished results. ${ }^{c}$ Mobility classified based on log $K_{\mathrm{oc}}$ determined by HPLC in this study unless indicated otherwise. ${ }^{d}$ Re-classified as not mobile based on no leaching in soil column experiment. ${ }^{e}$ Classified based on batch and leaching test. ${ }^{f}$ Mobility determined based on $\log K_{\mathrm{oc}}$ of different components of diesel oil. ${ }^{62}{ }^{g}$ Category 1 : for aquatic toxicity $\mathrm{EC}_{50}<1.0 \mathrm{mg} \mathrm{L}{ }^{-1}$, for terrestrial toxicity $\mathrm{EC}_{50} \leq 10 \mathrm{mg}$ per $\mathrm{kg}$ dry weight. ${ }^{h}$ Based on predicted acute aquatic toxicity (see Table S5† for details).

ent and mobile) substance. ${ }^{29}$ Quin-2Me does not raise concerns at the moment due to its biodegradability, while the risk of Quin-2Me-ph to contaminate drinking water would be low because of the immobility. No experimental data are currently available for $\mathrm{H}_{2}$-lean or intermediate forms of alkylcarbazoles, MLH- or MSH-based LOHC as well as indoline that could be used for preliminary hazard classification. In order to fill that gap we used a mathematical model (ECOSAR part of US EPA EPI Suite package ${ }^{63}$ ) to predict acute toxicity towards algae, invertebrates and fish. The exact values are presented in Table S5. $\dagger$ Based on these predicted values all alkylcarbazoleas well as MLH- and MSH-derivatives except ethylcarbazole (Car-2) would be classified as aquatic acute toxicity category 1 and therefore would fulfil the ' $\mathrm{T}$ ' criterion (Table 5). Based on model values Car-2 belongs to acute category 2 and indoline to acute category 3 , meaning none of them fulfils the ' $T$ ' criterion. So far, the accuracy of that predictions cannot be verified. Nevertheless, based on results obtained in vitro tests (in mammalian cell line) partially hydrogenated alkylcarbazoles seem to be approximately two orders of magnitude more toxic than $\mathrm{H}_{2}$-rich/lean quinaldine suggesting generally high toxicity. ${ }^{11}$

The components of each LOHC system tested present different characteristics in terms of persistence, mobility and toxicity (Table 5). More data are needed for a full-scale evaluation of the environmental and human risk, and for an overall hazard assessment at least two compound forms $\left(\mathrm{H}_{2}\right.$-rich and $\mathrm{H}_{2}$-lean) of each LOHC system should be taken into account, since they can differ considerably as was shown here for members of quinaldine-based LOHC system. So far based on available data the LOHC systems do not seem to be clearly less hazardous than fossil fuels such as diesels regarding the " $\mathrm{P}$, M, T" criterion (Table 5). However, the fact that LOHCs contribute to safer, high-capacity and long-term storage and transport of renewable energy, make them superior to fossil fuels. The less complex composition than that of fossil fuels ${ }^{11}$ would be another benefit for the hazard monitoring and management of these compounds in the environment.

\section{Conclusions}

Novel energy systems based on liquid organic hydrogen carrier (LOHC) technology have been developed recently for storage and transport of conventional or renewable energy. In many geographical locations, applications of LOHCs in stationary and mobile (vehicular) energy supply as well as in long-distance energy transport have been initiated. Given large scale of application and considerable release potential the environmental impact assessment of this technology is necessary. This study evaluated the adsorption and mobility in soil of a series of LOHC chemicals (quinaldines, indoles, alkylcarbazoles, benzyltoluenes and dibenzyltoluene in different $\mathrm{H}_{2}$ loading forms) which are considered most promising candidates. In silico model COSMO-RS is a useful tool for the prediction and screening of compounds' adsorption. Further investi- 
gations using HPLC-screening suggested the mobility based on the $K_{\mathrm{oc}}$ ranging from highly to not mobile with particular LOHC systems in following order: indoles $<$ quinaldines $<$ carbazole derivatives < benzyltoluenes < dibenzyltoluene. Additionally, soil affinity of quinaldine-based LOHC system was investigated in more detail using adsorption batch equilibrium and column leaching test (28 days). In combination with the findings in our previous studies on persistence and toxicity (aquatic and terrestrial), the fully saturated quinaldine - Quin-2Me-H10 - was classified as "PM" (persistent and mobile) chemical, which has potential of contaminating water sources due to lack of degradability and low retention in soils. Many other LOHC chemicals tested in this study, i.e. Quin2Me-ph, carbazole derivatives, benzyltoluene (the partially saturated form) and dibenzyltoluene, appeared to be rather immobile. For these compounds an accumulation close to the point of release may be expected if no significant degradation occurs and no imminent danger of contaminating water resources exist. Considering that within the LOHC system $\mathrm{H}_{2}$ rich and -lean forms are paired in reaction cycles and accompanied with intermediates (e.g., -ph), LOHCs released into the environment are very likely mixtures of the different forms. Therefore, the environmental hazard assessment of LOHC system needs to be based on the most hazardous compound (form) that might be used/produced within the cycle. In addition, the environmental hazard profile should be weighed against the socio-economic and technological improvements they offer in terms of reduced emissions, possibility of flexible long-term (renewable) energy storage and lower cost (economic/environmental) than many other options.

\section{Conflicts of interest}

The authors declare the following competing interest: Michael Diedenhofen is a scientist at BIOVIA, Dassault Systèmes Deutschland $\mathrm{GmbH}$, who is the developer of the COSMOtherm and distributor of the TURBOMOLE software packages.

\section{Acknowledgements}

This work was financially supported by the University of Bremen and the European Union FP7 COFUND within Marie Curie Actions BremenTrac Program (grant agreement No. 600411) and M8 Postoc-Initiatve PLUS (funded by the German Excellence Initiative) as well as the German Federal Foundation for the Environment (Deutsche Bundesstiftung Umwelt (DBU), Osnabrück/Germany). We would like to thank the entire UFT Team for the interdisciplinary cooperation. We acknowledge the working group of Prof. Dr Peter Wasserscheid for providing the LOHC chemicals. The authors would like to thank Dr Jan Köser for the support on MATLAB.

\section{References}

1 D. Teichmann, W. Arlt, P. Wasserscheid and R. Freymann, Energy Environ. Sci., 2011, 4, 2767-2773.

2 D. Teichmann, W. Arlt and P. Wasserscheid, Int. J. Hydrogen Energy, 2012, 37, 18118-18132.

3 Q. L. Zhu and Q. Xu, Energy Environ. Sci., 2015, 8, 478512.

4 M. Markiewicz, Y.-Q. Zhang, A. Bösmann, N. Brückner, J. Thöming, P. Wasserscheid and S. Stolte, Energy Environ. Sci., 2015, 8, 1035-1045.

5 L. Schlapbach and A. Züttel, Nature, 2001, 414, 353358.

6 M. S. Dresselhaus and I. L. Thomas, Nature, 2001, 414, 332-337.

7 I. Dincer, Renewable Sustainable Energy Rev., 2000, 4, 157175.

8 P. Preuster, C. Papp and P. Wasserscheid, Acc. Chem. Res., 2017, 50, 74-85.

9 D. Geburtig, P. Preuster, A. Bösmann, K. Müller and P. Wasserscheid, Int. J. Hydrogen Energy, 2016, 41, 10101017.

10 P. M. Modisha, C. N. M. Ouma, R. Garidzirai, P. Wasserscheid and D. Bessarabov, Energy Fuels, 2019, 33, 2778-2796.

11 M. Markiewicz, Y.-Q. Zhang, M. T. Empl, M. Lykaki, J. Thöming, P. Steinberg and S. Stolte, Energy Environ. Sci., 2019, 12, 366-383.

12 K. M. Eblagon, D. Rentsch, O. Friedrichs, A. Remhof, A. Zuettel, A. J. Ramirez-Cuesta and S. C. Tsang, Int. J. Hydrogen Energy, 2010, 35, 11609-11621.

13 A. Fikrt, R. Brehmer, V.-O. Milella, K. Müller, A. Bösmann, P. Preuster, N. Alt, E. Schlücker, P. Wasserscheid and W. Arlt, Appl. Energy, 2017, 194, 1-8.

14 K. Müller, K. Stark, V. N. Emel'yanenko, M. A. Varfolomeev, D. H. Zaitsau, E. Shoifet, C. Schick, S. P. Verevkin and W. Arlt, Ind. Eng. Chem. Res., 2015, 54, 7967-7976.

15 M. Niermann, A. Beckendorff, M. Kaltschmitt and K. Bonhoff, Int. J. Hydrogen Energy, 2019, 44, 66316654.

$16 \mathrm{P} . \mathrm{Hu}, \mathrm{E}$. Fogler, Y. Diskin-Posner, M. A. Iron and D. Milstein, Nat. Commun., 2015, 6, 1-7.

17 B. Verheul, Overview of hydrogen and fuel cell developments in China, Shanghai, 2019.

18 Japan launches first global hydrogen supply chain demo project; liquid organic hydrogen carrier (LOHC) technology, https:/www.greencarcongress.com/2017/07/ 20170728-ahead.html, (accessed 27 August 2020).

19 G. Ozin, Hydrogen Storage in Liquid Organic Hydrogen Carriers, https://www.advancedsciencenews.com/hydrogenstorage-liquid-organic-hydrogen-carriers/, (accessed 27 August 2020).

20 From the Lab to the Rails, https://www.fz-juelich.de/ SharedDocs/Pressemitteilungen/UK/EN/2018/2018-04-19-lohczug.html;jsessionid=44F4EA2C24CF9E831CC0FDA63FB4E06D, (accessed 27 August 2020). 
21 V. Leung, LOHC technology implemented in China, https:// www.gasworld.com/lohc-technology-implemented-in-china/ 2014010.article, (accessed 27 August 2020).

22 J. Sampson, Hydrogen mobility infrastructure for China, https:// www.gasworld.com/hydrogen-mobility-infrastructure-for-china/ 2014052.article, (accessed 27 August 2020).

23 N. Brückner, K. Obesser, A. Bösmann, D. Teichmann, W. Arlt, J. Dungs and P. Wasserscheid, ChemSusChem, 2014, 7, 229-235.

24 A.-K. Reineke, A. Preiss, M. Elend and J. Hollender, Chemosphere, 2008, 70, 2118-2126.

25 S. T. J. Droge and K.-U. Goss, Environ. Sci. Technol., 2013, 47, 798-806.

26 S. T. J. Droge and K.-U. Goss, Environ. Sci. Technol., 2013, 47, 14233-14241.

27 M. Hörsing, A. Ledin, R. Grabic, J. Fick, M. Tysklind, J. L. C. Jansen and H. R. Andersen, Water Res., 2011, 45, 4470-4482.

28 Y.-Q. Zhang, M. Markiewicz, J. Filser and S. Stolte, Environ. Sci. Technol., 2018, 52, 258-265.

29 M. Neumann and I. Schliebner, Protecting the sources of our drinking water-a revised proposal for implementing criteria and an assessment procedure to identify persistent, mobile and toxic (PMT) and very persistent, very mobile (vPvM) substances registered under REACH, German Environment Agency, Dessau-Rosslau, 2017.

30 H. P. H. Arp, T. N. Brown, U. Berger and S. E. Hale, Environ. Sci.: Processes Impacts, 2017, 19, 939-955.

31 H. P. H. Arp, Preliminary assessment of substances registered under REACH that could fulfil the proposed PMT/vPvM criteria, Norwegian Geotechnical Institute, Oslo, 2018.

32 OECD, Test No. 121: Estimation of the Adsorption Coefficient (Koc) on Soil and on Sewage Sludge using High Performance Liquid Chromatography (HPLC), OECD Guidelines for the Testing of Chemicals, Section 1, OECD Publishing, Paris, 2001, DOI: 10.1787/9789264069909-en.

33 OECD, Test No. 106: Adsorption - Desorption Using a Batch Equilibrium Method, OECD Guidelines for the Testing of Chemicals, Section 1, OECD Publishing, Paris, 2000, DOI: 10.1787/9789264069602-en.

34 OECD, Test No. 312: Leaching in Soil Columns, OECD Guidelines for the Testing of Chemicals, Section 3, OECD Publishing, Paris, 2004, DOI: 10.1787/9789264070561-en.

35 ChemAxon, MarvinSketch v 14.10.6.0, 2014.

36 Environmental Protection Agency, Understanding variation in partition coefficient, $K_{d}$, values - Volume I: The $K_{d}$ Model, Methods of Measurement, and Application of Chemical Reaction Codes, 1999, vol. I.

37 The R Foundation, The $R$ Project for Statistical Computing R-4.0.o for Microsoft $\AA$ Windows, 2020.

38 P. J. McCall, R. L. Swann, D. A. Laskowski, S. M. Unger, S. A. Vrona and H. J. Dishburger, Bull. Environ. Contam. Toxicol., 1980, 24, 190-195.

39 W. Kördel, G. Kotthoff and J. Müller, Chemosphere, 1995, 30, 1373-1384.
40 G. Jones, The Chemistry of Heterocyclic Compounds, Quinolines, Wiley-Interscience, 1991, vol. 32.

41 J. Tolls, Environ. Sci. Technol., 2001, 35, 3397-3406.

42 M. Kuśmierz, P. Oleszczuk, P. Kraska, E. Pałys and S. Andruszczak, Chemosphere, 2016, 146, 272-279.

43 W. D. Weissenfels, H.-J. Klewer and J. Langhoff, Appl. Microbiol. Biotechnol., 1992, 36, 689-696.

44 D. M. Revitt, T. Balogh and H. Jones, Environ. Sci. Pollut. Res., 2014, 21, 4209-4219.

45 K. Kobetičová, J. Bezchlebová, J. Lána, I. Sochová and J. Hofman, Ecotoxicol. Environ. Saf., 2008, 71, 650-660.

46 European Centre for Ecotoxicology and Toxicology of Chemicals, Environmental Exposure Assessment of Ionisable Organic Compounds - Technical Report No. 123, Brussels, 2013.

47 T. A. T. Aboul-Kassim and B. R. T. Simoneit, in PollutantSolid Phase Interactions Mechanisms, Chemistry and Modeling, Springer Berlin Heidelberg, 2001, pp. 107-167.

48 D. Liu, J. Gui and Z. Sun, J. Mol. Catal. A: Chem., 2008, 291, 17-21.

49 M. Matzke, K. Thiele, A. Müller and J. Filser, Chemosphere, 2009, 74, 568-574.

50 B. Styrishave, T. Hartnik, P. Christensen, O. Andersen and J. Jensen, Environ. Toxicol. Chem., 2010, 29, 1084-1090.

51 K. Vancampenhout, K. Wouters, B. De Vos, P. Buurman, R. Swennen and J. Deckers, Soil Biol. Biochem., 2009, 41, 568-579.

52 I. N. Anyanwu and K. T. Semple, Environ. Technol. Innov., 2015, 3, 108-120.

53 A. B. Thomsen, K. Henriksen, C. Grøn and P. Møldrup, Environ. Sci. Technol., 1999, 33, 2891-2898.

54 M. Markiewicz, C. Jungnickel, C.-W. Cho and S. Stolte, Environ. Sci.: Processes Impacts, 2015, 17, 1462-1469.

55 P. Grathwohl and B. Susset, Waste Manage., 2009, 29, 26812688.

56 W. Kördel, C. Bernhardt, K. Derz, K. Hund-Rinke, J. Harmsen, W. Peijnenburg, R. Comans and K. Terytze, J. Hazard. Mater., 2013, 261, 854-862.

57 H. Rüdel, W. Körner, T. Letzel, M. Neumann, K. Nödler and T. Reemtsma, Environ. Sci. Eur., 2020, 32, 1-11.

58 U. Berger, N. Ost, D. Sätteler, I. Schliebner, R. Kühne, G. Schüürmann, M. Neumann and T. Reemtsma, Umweltbundesamt, Texte, 2018, 9, 1-61.

59 S. Fetzner, Appl. Microbiol. Biotechnol., 1998, 49, 237250.

60 J. Kim, H. Hong, A. Heo and W. Park, FEMS Microbiol. Lett., 2013, 343, 89-99.

61 A. J. Reinecke, M. Van Wyk and S. A. Reinecke, Bull. Environ. Contam. Toxicol., 2016, 96, 804-809.

62 European Chemicals Agency (ECHA), Fuels, diesel Adsorption/desorption, https://echa.europa.eu/registrationdossier/-/registered-dossier/7243/5/5/2, (accessed 27 August 2020).

63 US EPA Estimation Programs Interface SuiteTM for Microsoft ${ }^{\circledR}$ Windows EPI Suite ${ }^{\mathrm{TM}} \mathrm{V}$ 4.1, 2014. 